\title{
A Comparison of Formative Vocabulary Tests as Credited and Non-Credited Assessment Tasks: Japanese as a Second/Foreign Language at Tertiary Level
}

\author{
Hiroshi Hasegawa
}

\begin{abstract}
The aim of this research was to identify whether regularly implemented credit-bearing assignment tasks have any influence on students' learning outcomes and their perceptions of vocabulary learning in Japanese as a second/foreign language education. The target assignment task was vocabulary learning through regularly implemented testing. This was attempted with two research objectives (RO). RO1 was to compare and contrast the differences in the academic results of students required to complete the same vocabulary tests, but with one group doing so for credit and the other not receiving credit. $\mathrm{RO} 2$ was to explore the opinions of students who experienced tasks organised in similar situations but with contrasting purposes, namely one purpose being to do the tasks to earn credit and the other not earning credited. The results suggest that the assignment task conditions changed by the university policy to do tasks that are not assessed may have a negative impact on students' learning. These findings offer strong support for the suggestion to return to the earlier practice of considering credit-bearing assignments for students' final subject marks.
\end{abstract}

Index Terms-Credited assessment tasks, vocabulary, Japanese as a second/foreign language, autonomous learning.

\section{INTRODUCTION}

Federal government pressure for institutional financial cuts is forcing universities in Australia to invent new operational strategies in order to maintain academic courses. A simple, and commonly occurring, option in response to the policy is to make some subjects redundant. Having fewer options on offer in an academic course leads to lower numbers of academic staff being involved in teaching activities. Cramming higher numbers of students into classes is another controversial but common practice (e.g., [1], [2]), in an attempt to reduce the weekly teaching hours of academics. The numbers of subjects and contact hours are reduced; in particular, many universities in Australia compel subject/course coordinators to make significant modifications to their subject assignment tasks while still expecting them to maintain high-quality teaching and satisfactory achievement of student learning outcomes. These modifications may involve the subject content and style of the assignments, as well as the total number of assignments. The majority of students favours having fewer

Manuscript received October 10, 2016; revised December 10, 2016.

Hiroshi Hasegawa is with the School of Education, Curtin University, Western Australia (e-mail: h.hasegawa@curtin.edu.au). assignment tasks per subject, while has led to the strategy of making the offered subjects sound 'less-difficult-to-pass' in order to attract more students. Under the guise of delivering subjects effectively and compactly, using a variety of IT facilities, minimising the number of assessment tasks is a common practice in many universities in Australia.

In such a university culture, decisions about subject content and assignments are made frequently by faculty management teams in a top-down manner, challenging subject/course coordinators to redesign their approaches. The switching of assignment status from 'credit bearing' to 'non-credit bearing' is one of the strategies used in order to keep the assignment tasks that are crucial to the students' grasp of the subject. However, this may have adverse effects on students' attitudes to their subject learning, which may eventually consequence their academic outcomes. The aim of this research was to identify whether regularly implemented credit-bearing assignment tasks have any influence on students' learning outcomes and their perceptions of vocabulary learning of a second/foreign language. The target subject for this research was Japanese as a second/foreign language at university level. The aim was addressed through two research objectives (RO). RO1 was to compare and contrast the differences in the academic results of students required to complete the same vocabulary tests, but with one group doing so for credit and the other not receiving credit. $\mathrm{RO} 2$ was to explore the opinions of students who experienced tasks organised in similar situations but with different purposes, namely one purpose being to do the tasks to earn credit and the other not earning credit.

\section{VocABUlary KNOWLEDGE CHECK IN ACADEMIC ClASSROOM SETTING}

Several recent studies have concentrated on effective teaching strategies for second/foreign language education. One aspect, vocabulary acquisition, is an essential component of target language learning. Learners' sense of difficulty in the target language usage largely involves vocabulary knowledge, as their word knowledge plays a decisive role in enhancing their confidence as well as both receptive and productive skills in the language [3]. Although vocabulary learning was neglected as an important part of second/foreign language learning in the past, it has become one of the most dominant current research areas in second/foreign language education. Some studies have shown that learners need multiple opportunities to encounter target words through engaging in classroom 
activities, and this is especially the case where the teacher plays an active role [4]-[8]. However, there is commonly insufficient teaching/learning time for students' vocabulary learning and acquisition during contact hours in class, especially in higher education where there are strict constraints on the number of classroom teaching hours allocated in the interest of saving the faculty's management costs. Managerialism in universities has been in Australia over the past 20 years, and internal governance rules based on the Commonwealth and State legislation that apply not only to the trading corporations but also to tertiary education sectors, have resulted in a variety of academic drawbacks (e.g., [9], [10]). These managerial practices has been prevailing across university disciplines and lexical identity itself has been overshadowed by a commonly promoted and encouraged practice of emphasising autonomous and independent learning. As a consequence, various researchers have turned their attention to the role of autonomous learning, and this has been reflected in the field of foreign language education (e.g., [11]-[14]). Despite the fact that 'contact hours and levels of autonomy required ... vary considerably across discipline areas' ([15], p. 3), and irrespective of whether it functions well only for certain academic conditions i.e. larger class sizes, lower/beginners undergraduate levels [16] (as cited in [17]), many educators in higher education institutions in Australia are enforced to design their teaching approaches to engage students not only in but also outside class. In the case of second/foreign language education this has resulted in assigning vocabulary acquisition through rote learning as students' independent self-study. Despite the negative connotation attached to rote learning broadly, in educational field [18], there has been progressive interest in identifying its beneficial aspects. Reference [19] emphasizes that '... rote learning of vocabulary... may be entirely appropriate at the early stages of learning a second language' (as cited in [20], p. 237), which applied to the subject assignment focused by this research.

As an indicator of learners' vocabulary knowledge, the vocabulary knowledge scale (VKS), a measure of metamorphosis on a continuum of vocabulary acquisition [21], is one of the most frequently employed instruments in current research on second/foreign language learners' productive/receptive vocabulary knowledge. This instrument, introduced by Paribakht and Wesche [22] and developed further by Wesche and Paribakht [23], originated from Dale's [24] conceptualization of word knowledge. Vocabulary knowledge is divided into a minimum of four stages: Stage 1 - Never having seen the term before; Stage 2 - Knowing there is such a word, but not knowing what it means; Stage 3 - Having a context-bound and vague knowledge of the word's meaning; and Stage 4 - Knowing the word well and remembering it (as cited in [25], p. 567). In order to initiate the first stage, teachers usually attempt to create occasions for their students to encounter lists of target vocabulary outside their class time. It is critical for them to be motivated to do this and, as a result, their vocabulary acquisition is checked through vocabulary tests targeted by this research, aimed at increasing their vocabulary knowledge, especially for the first stage.

\section{RESEARCH OBJECTIVES, PARTICIPANTS AND METHODOLOGY}

The target subject study of this research was Japanese as a second/foreign language at a university in Australia. Japanese language study requires learners to acquire three writing characters based on two orthographic systems, Hiragana and Katakana (both syllabary) and Kanji (logography). This research focused on Japanese vocabulary learning and testing, concentrating mainly on Hiragana and Katakana. There are 46 basic letters in each Japanese syllabary, representing 25 voiced syllables, and the total of 71 symbols for each type of syllabary, aka Kana [26]. The pedagogical approach to vocabulary knowledge categorises words as high frequency words, low-frequency words, and specialized vocabulary [11] and receptive and productive (or expressive) vocabulary. Despite its clear division, this categorisation is not accepted by some researchers [27] who tend to focus on the correlation between the large number of low-frequency words and small number of high-frequency words, and advocate the ideal theory of vocabulary selection: a large number of high-frequency words, as high-frequency words are 'very important because these words cover a very large portion of the running words in spoken and written texts [11]. In addition, interpretation of high-frequency words involves a comparison of the quantity of receptive and productive words, and this leads to the pedagogical argument that learners tend to gain more receptive vocabulary knowledge if they learn vocabulary receptively rather than productively [21], [28] and vice versa. Another consideration is that factors such as time length should contribute to other findings [28]: receptive vocabulary knowledge was promoted more effectively by the learning tasks focusing on receptive knowledge while the form of productive and receptive vocabulary and in-depth productive knowledge were both enhanced by productive learning tasks [29]. Furthermore, most researchers seem to have been convinced that acquiring the meaning and form of a word does not mean that one knows the correct use of the word [28]. Disregarding the type of vocabulary knowledge, however, a sizable portion of the vocabulary in the target language should be acquired quickly, especially by learners at the beginner level, since sentence production with its associated syntax, forms, orthography, meaning, and grammatical functions, involves a certain amount of vocabulary knowledge which enables the target language to be more comprehensible [6]. Also, the learner's performance in the skills of listening, speaking, reading, and writing can be correlated with a richer vocabulary knowledge [30]. The research literature on vocabulary knowledge has argued extensively about whether to view vocabulary knowledge in terms of 'breadth (how many words)' or 'depth (how well known)' ([21], para. 10) (e.g., [23], [31], [32]), which should convince us that both should be considered in parallel for vocabulary learning. This research concentrates only on vocabulary tests as the breadth aspect; an assignment in a formal academic classroom setting. Within contrasts to advanced-level Japanese, the beginners' level of Japanese as a second/foreign language addresses students who are less exposed to environments with rich linguistic input, such as studying abroad or in an intensive domestic immersion 
program. Therefore, students in $1^{\text {st }}$ and $2^{\text {nd }}$ year Japanese classes whose knowledge of vocabulary is acquired primarily through in-class instruction naturally became suitable participants in this research.

There were two main research objectives (RO) in this research. RO1 was to compare the differences in the academic performances/outcomes of multiple student groups from the credited Vocabulary Test (VT) in Semester 1 of 2014 to the non-credited Vocabulary Check (VC) in Semester 2 of 2015. RO2 was to compare the perceptions of students who had experienced the transition period from the credited Vocabulary Test (VT) in Semester 1 of 2014 to the non-credited Vocabulary Check (VC) in Semester 2 of 2015. Currently, the administrators of some universities in Australia have placed restrictions on the numbers of regular, credit-bearing tests due to their policies of limiting the total numbers of assignment tasks. This policy, as applied to the vocabulary test as an assignment, was the subject of this research; taking place only as non-credited exercise, if it needs to be retained. This issue also became a focus of this research.

The tests used as the focus of this research were the weekly Vocabulary Tests (VT) of the $1^{\text {st }}$ and $2^{\text {nd }}$ year Japanese subjects offered at Curtin University in Western Australia. These VTs were introduced as credited assessment tasks, directly linked to the final subject mark in 2014. Later, they were conducted as non-assessable practice tasks with an altered name, Vocabulary Check (VC), in 2015. In other words, regular occasions for students to study and master the target vocabulary were still provided throughout Semester 2 in 2015, as previously, but the 2015 students were required to be more autonomous and selfdisciplined in order to maintain their skills, since they did not have the extrinsic motivation of the assessment credit that the 2014 students had (Refer to Table I.)

TABLE I: TARGET VOCABULARY TEST/CHECK

\begin{tabular}{|c|c|c|}
\hline & $\begin{array}{c}\text { Semester 2 in 2014 } \\
\text { (Credited } \\
\text { assessment) }\end{array}$ & $\begin{array}{c}\text { Semester 2 in 2015 } \\
\text { (Non-credited } \\
\text { assessment) }\end{array}$ \\
\hline $\begin{array}{c}\mathbf{1}^{\text {st }} \text { year Japanese } \\
\text { subject }\end{array}$ & VT & VC \\
\hline $\begin{array}{c}\mathbf{2}^{\text {nd }} \text { year Japanese } \\
\text { subject }\end{array}$ & VT & VC \\
\hline
\end{tabular}

The following procedures were used in the research: (1) manual computation of the numbers in each category before computing the frequencies using SPSS, (2) outcomes of the VT (credited) conducted in Semester 2, 2014 as well as those of the VC (non-credited) in Semester 2, 2015, (3) summaries of the data from the academic records of the target students/tests in 2014 and 2015, (4) importing information from an Excel file into the SPSS file, (5) computing the frequency and percentage for the dark yellow sections using the SPSS file, and (6) categorising the rest of the information into relevant categories before computing the frequencies of different responses.

\section{A. Research Participants: RO1}

RO1 was to compare the differences in students' academic performances/outcomes in VT (credited) and VC (non-credited). The students targeted by RO1 had undertaken the $1^{\text {st }}$ year of Japanese in Semester 2, 2014 and
2015. A comparison was also made between the performance of the 2nd year students' VT and VC taken in Semester 2, 2014 and 2015, respectively.

The analyses involved categorising information and computing frequencies using SPSS, comparing and contrasting the differences between performances in the target assignments. The students were divided into four groups: Groups A and B consisted of the $1^{\text {st }}$ year Japanese students who took the VT in Semester 2, 2014 and the VC in Semester 2, 2015. Groups $C$ and D comprised the $2^{\text {nd }}$ year students who took the VT in Semester 2, 2014 and the VC in Semester 2, 2015 (see Table II below). Thus, comparisons were made between Group A and Group B, as well as between Group C and Group D.

TABLE II: TARGET RESEARCH PARTICIPANT GROUPS

\begin{tabular}{|c|c|}
\hline $\begin{array}{c}\text { Participant } \\
\text { Groups }\end{array}$ & Group Description \\
\hline Group A & $1^{\text {st }}$ year students who took VT in Semester 2, \\
& 2014 \\
\hline Group B & $1^{\text {st }}$ year students who took VC in Semester 2, \\
& 2015 \\
\hline Group C & $2^{\text {nd }}$ year students who took VT in Semester 2, \\
& 2014 \\
\hline Group D & $2^{\text {nd }}$ year students who took VC in Semester 2, \\
& 2015 \\
\hline
\end{tabular}

\section{B. Research Participants: RO2}

$\mathrm{RO} 2$ was to compare the perceptions of students who had experienced the transition period from the VC in Semester 1, 2014 to the VT in Semester 2, 2015. These student groups were equivalent to Group B and Group D, described in Table II above. These students were categorised as Group E and Group F, as shown in Table III.

To investigate RO2, a survey was conducted, targeting the students of Group E and Group F. The survey consisted of two sections about the students' concepts of vocabulary, one measuring their preferences and the other the shifts in their perceptions/attitudes. The former included three questions; 1. Do you wish the coordinator to organise regular vocabulary tests? 2. How many times do you personally wish the subject coordinator to organise vocabulary tests? and 3. Do you wish the subject coordinator to organise vocabulary tests as credited tests? The second section used a 5-point Likert Scale (1: least agreement and 5: most agreement) and questioned the students' personal agreement with the following three statements: 1. Vocabulary tests motivate my regular vocabulary learning if they are credited/non credited, 2 . Vocabulary tests affect my academic results if they are credited/non credited, and 3 . Vocabulary tests affect my vocabulary study time if they are credited/non credited.

TABLE III: TARGET RESEARCH PARTICIPANT GROUPS

\begin{tabular}{|c|c|}
\hline Participant Groups & Group Description \\
\hline $\begin{array}{c}\text { Group E } \\
(=\text { Group B of TABLE II) }\end{array}$ & $\begin{array}{c}1^{\text {st }} \text { year students who took VT in Semester } \\
1,2015 \text { and VC in Semester 2, } 2015\end{array}$ \\
\hline $\begin{array}{c}\text { Group F } \\
(=\text { Group D of TABLE II) }\end{array}$ & $\begin{array}{c}2^{\text {nd }} \text { year students who took VT in Semester } \\
1,2015 \text { and VC in Semester 2, 2015 }\end{array}$ \\
\hline
\end{tabular}

The research analyses involved categorising information and computing frequencies using SPSS to compare and contrast the responses of the two groups $\mathrm{E}$ and $\mathrm{F}$ in Table III. 


\section{RESULTS}

This section outlines the results for the groups in response to $\mathrm{RO} 1$ and $\mathrm{RO} 2$.

\section{A. In Response to RO1}

TABLE IV: MEANS AND SD OF TARGET RESEARCH PARTICIPANT GROUPS

\begin{tabular}{|c|c|c|}
\hline & Mean & SD \\
\hline Group A & 15.24 & 3.74 \\
\hline Group B & 14.41 & 4.45 \\
\hline Group C & 15.95 & 3.64 \\
\hline Group D & 9.77 & 5.55 \\
\hline
\end{tabular}

Comparing the marks achieved by Groups A and B in terms of their target vocabulary, there was no significant difference between the two groups [Mean (Group A) = 15.24, SD $($ Group A) $=3.74$; Mean $($ Group B $)=14.41$, SD $($ Group B $)=4.45 ; t=0.97, p>0.05]$.

On the other hand, when comparing the marks achieved by Groups $\mathrm{C}$ and $\mathrm{D}$, a significant difference between the two groups was evident [Mean (Group C) $=15.95$, SD $($ Group C $)=3.64$; Mean $($ Group D) $=9.77$, SD $($ Group D $)=$ 5.55; $t=5.63, p<0.01]$.

This section outlines the results for the groups in response to $\mathrm{RO} 1$ and $\mathrm{RO} 2$.

\section{B. Comparison Marked Achieved bylst year Students in 2014 with those in 2015}

Table IV above shows that there was no significant difference in the means of the 1 st year students who took the VT in Semester 2, 2014 (= Group A) and those who took the VC in Semester 22015 (= Group B). (Group A: Mean $=15.24, \mathrm{SD}=3.74$, while Group $\mathrm{B}:$ Mean $=14.41$, $\mathrm{SD}=4.45 ; t=0.97, p>0.05$.) This result indicates that the formats of the tests (credited or non-credited towards their result) did not affect the students' approach towards their study of vocabulary because they maintained high mean scores regardless of whether the tests were credited bearing or not. The following contributing factors should be considered in relation to this outcome.

The primary contributing factor to the students' unchanged attitude towards VT and VC may be related to the number of words, the breadth of vocabulary knowledge required by this subject at the total beginners' level. The size of vocabulary knowledge is critical to participating in exercises and activities during class, especially for learners at the fundamental level of foreign language learning. Unlike the wide range of lexical forms such as morphemes, idioms, set-up expressions and catchphrases introduced at the higher level, the content introduced at this beginner level is straightforward and consists mainly of uncomplicated lexicons (and grammar structures). Naturally, most of the vocabulary encountered week after week, which is to be memorised by rote learning and monitored via vocabulary tests/checks, is considered as high-frequency vocabulary, and is used frequently during their practice in and outside of class. This brings about their cognition that their insufficient automaticity in communicating in the target language at this level derives from not only their limited abilities in producing and comprehending sentences [33] or lack of general communicative strategies for coping with interactions but predominantly from their deficient vocabulary knowledge. Therefore, any perplexities and errors they encounter immediately remind them of the importance of vocabulary knowledge. Compared with those at higher levels of study, students with smaller vocabularies can stay up-to-date with their Japanese study easily while self-assessing their own progress and self-monitoring their study using the subject's testing system. This, in turn, has a direct influence on sustaining constant and positive attitudes towards studying vocabulary, regardless of whether or not it is a formally assessed component of the subject.

The high mean score regardless of the difference between VT and VC could be due to the Japanese learning background of the $1^{\text {st }}$ year students. This subject targets students who have not studied Japanese previously. A description of the target student group (total beginners of Japanese) assists students' choice of the appropriate level of Japanese at university, although it does not entirely exclude students who have already acquired some knowledge of Japanese. For example, students are eligible to enrol in this subject if they wish to continue their learning of Japanese after having undertaken a compulsory Japanese subject at primary and/or high school level. This $1^{\text {st }}$ year subject is considered appropriate for them since, at the time of enrolment, their Japanese proficiency level does not qualify them for a higher level Japanese subject provided by the university. In addition, students who may have had exposure to Japanese in unofficial settings and are able to converse in broken colloquial Japanese are also allowed to take this subject, as they generally lack sufficient knowledge and mastery of Japanese syntax or literacy skills. Moreover, the nature of this subject, which caters to a diversity of previous Japanese learning experiences, attracts students searching for an elective subject required by their non-Japanese related major course of study. The distinction between VT and VC does not inconvenience students with past Japanese study experience because of the short amount of time required for them to prepare for each VT and $\mathrm{VC}$, unlike total beginner students with no previous Japanese study experience. It is highly probable that the former group of students contributed to the high scores in both VT and VC, regardless of whether the test is a part of the formal assessment for the subject.

\section{C. $R O 1=$ Comparison of Marks Achieved by $2^{\text {nd }}$ Year Students in 2014 with those in 2015}

Unlike the $1^{\text {st }}$ year students' VT and VC results presented above, a significant difference between the two groups $\mathrm{C}$ and D, was clearly evident. Table IV shows that Group C achieved a mean of $15.95, \mathrm{SD}=3.64$, while Group D achieved a Mean of 9.77, $\mathrm{SD}=5.55 ; t=5.63, p<0.01$.

Students enrolled in courses at university have the fundamental goal to attain their degree(s) in their chosen discipline(s). In order to achieve this goal, they have to meet the requirement to complete specific academic assignments/tasks. Universities offer multiple levels of grades to reflect academic achievement (a 'pass' that usually ranges from 50 to 100 , subject to conditions). It is common for university students to put in less than their maximum effort, choosing just to pass rather than achieve the highest possible academic grade. In other words, they are prone to apply minimum effort and are satisfied as long as they do not fail the subject. The majority of students has this low expectation can be ascertained by the fact that official complaints regarding academic results are lodged in 
most cases when students fail a subject, rather than when they wish to challenge the award of a pass mark which they believe should be higher.

A large number of students enrolled in the $2^{\text {nd }}$ year Japanese subjects have completed other Japanese subjects (at lower levels). In addition, the majority of students enrolled in the target subject of this research: a $2^{\text {nd }}$ year Semester 2 subject, undertook the $2^{\text {nd }}$ year Semester 1 subject. These two subjects share similar structures and are taught by the same lecturer/tutor. Familiarity with the structure of the subject, and with the pedagogical theories and practices of teaching staff already known to students, may have contributed to a reduction of any psychological pressure which they may otherwise have felt towards the subject. The reduced sense of stress, as a result of previous exposure, enabled them to approach the subject with confidence. Thus they must have felt that, with only minor effort in the non-assessed tasks (such as the weekly vocabulary check), they would be able to acquire a 'pass' grade.

\section{In Response to $\mathrm{RO} 2$}

TABLE V. STUdENTS' PREFERENCES FOR THE REgular VocABULARY TESTS

\begin{tabular}{|c|c|c|}
\hline & Group E & Group F \\
\hline Number of students & 20 & 36 \\
\hline Percentage & $87.0 \%$ & $94.7 \%$ \\
\hline
\end{tabular}

Group E in Table V was made up of $1^{\text {st }}$ year students who took VT in Semester 1 and VC in Semester 2, 2015, while Group F was comprised of $2^{\text {nd }}$ year students who took VT in Semester 1, 2015 and VC in Semester 2, 2015. In answer to the question 'Do you wish the subject coordinator to organise regular vocabulary tests?' the majority of the students responded that they did, with $87.0 \%$ (20 students) of Group E and 94.7\% (36 students) of Group F saying 'yes'. This is fascinating, considering the fact that, in class, the students sometimes overtly expressed their antipathy to the tests. This result suggests that while the vocabulary tests or checks are not entirely welcome, they are taken positively and regarded as important for enhancing motivation in language study.

TABLE VI. Vocabulary Test Frequency Preferred by Group E

\begin{tabular}{|c|c|c|}
\multicolumn{3}{|c|}{ GTUDENTS } \\
\hline \multicolumn{3}{|c|}{ Group E } \\
\hline Frequency & No. of students & Percentage \\
\hline Once & 14 & $60.9 \%$ \\
\hline Twice & 3 & $13.0 \%$ \\
\hline Three times & 3 & $13.0 \%$ \\
\hline Four times & 1 & $4.5 \%$ \\
\hline
\end{tabular}

TABLE VII. VOCABUlary TEST FREQUENCY PREFERRED By GROUP F STUDENTS

\begin{tabular}{|c|c|c|}
\hline \multicolumn{3}{|c|}{ Group F } \\
\hline Frequency & No. of students & Percentage \\
\hline Once & 22 & $57.9 \%$ \\
\hline Twice & 10 & $26.3 \%$ \\
\hline Three times & 4 & $10.5 \%$ \\
\hline
\end{tabular}

In Tables VI and VII, similar percentages of Groups E and $\mathrm{F}$ preferred tests to be held once a week (Group E: 60.9\%/ 14 students, Group F: 57.9\%/ 22 students) or multiple times a week (Group E: 30.5\%/ 7 students, Group F: 36.8\%/ 14 students). The one student in Group E (Table
VI) is possibly a mistake, as lessons in the year the survey was conducted were held only twice a week with one 1-hour lecture and one 2-hour tutorial. In other words, tests could be held only twice a week, one in each session or even just once a week. From a practical perspective, the more elementary the level of Japanese taught, the more time is needed to introduce and teach new vocabulary. Therefore, it is impossible to hold vocabulary tests at multiple points within a lesson unless there is a major change in the subject design and assignment structure.

TABLE VIII. STUdENTS' PREFERENCES FOR CREDITED VOCABULARY

\begin{tabular}{|c|c|c|}
\hline \multicolumn{3}{|c|}{ TESTS } \\
\hline $\begin{array}{c}\text { Number of } \\
\text { students }\end{array}$ & 13 & Group F \\
\hline Percentage & $56.5 \%$ & 30 \\
\hline
\end{tabular}

Table VIII above shows students' preferences for the vocabulary test to be credited. 56.5\% (13 students) in Group $\mathrm{E}$ and $78.9 \%$ (30 students) in Group $\mathrm{F}$ favoured creditbearing tests. A possible reason for this difference is that many students in Group E preferred being absent from the lessons whenever they wished to do so, with no academic pressure to attend classes. As explained above, most students set themselves the goal of putting in the least possible effort to obtain a pass in the subject.

It is also noteworthy to examine the students' preferences for credited vocabulary tests (Table VIII) in relation to their preferences for regular vocabulary tests (Table V, which shows $87.0 \%$ (20 students) of Group E and 94.7\% (36 students) of Group $\mathrm{F}$ preferring regular tests). Group $\mathrm{E}$ showed a significant decline $(-30.5 \%)$ while Group F maintained a high percentage of students who preferred credited tests. This indicated that a large number of students in Group E considered the vocabulary test as an important occasion for them to study, although their perception towards vocabulary tests changed to a less positive one in a given context and test condition.

TABLE IX. SHIFTS IN THE PERCEPtiOns/AtTITUdes OF THE STUdENTS

\begin{tabular}{|c|c|c|}
\multicolumn{2}{c}{ GROUPS } & \multicolumn{2}{c|}{ Mean } \\
\cline { 2 - 3 } Perceptions/Attitudes & Group E & Group F \\
\hline $\begin{array}{c}\text { Vocabulary tests motivate my regular } \\
\text { vocabulary learning if they are credited }\end{array}$ & 4.26 & 4.63 \\
\hline $\begin{array}{c}\text { Vocabulary tests motivate my regular } \\
\text { vocabulary learning if they are non- } \\
\text { credited }\end{array}$ & 2.96 & 2.61 \\
\hline $\begin{array}{c}\text { Vocabulary tests affect my academic } \\
\text { results if they are credited }\end{array}$ & 4.35 & 4.39 \\
\hline $\begin{array}{c}\text { Vocabulary tests affect my academic } \\
\text { results if they are non-credited }\end{array}$ & 2.65 & 2.95 \\
\hline $\begin{array}{c}\text { Vocabulary tests affect my vocabulary } \\
\text { study time if they are credited }\end{array}$ & 4.26 & 4.13 \\
\hline $\begin{array}{c}\text { Vocabulary tests affect my vocabulary } \\
\text { study time if they are non-credited }\end{array}$ & 2.83 & 2.81 \\
\hline
\end{tabular}

TABLE X. STUDENTS' COMMENTS

\begin{tabular}{|c|c|}
\hline No & Comments \\
\hline 1 & No difference. \\
\hline 2 & If they are not credited, I/students will not study. \\
\hline 3 & If they are credited, I/students will study more/regularly. \\
\hline 4 & Motivate students to study harder and/or more often. \\
\hline 5 & Motivate students to attend class. \\
\hline 6 & Help to check/keep them on track. \\
\hline 7 & No test, no study. \\
\hline 8 & Useful/helpful/good/easy and useful. \\
\hline
\end{tabular}




\begin{tabular}{|c|c|}
\hline 9 & Good discipline. \\
\hline 10 & The credited test is worth too much value \\
\hline 11 & $\begin{array}{c}\text { If they are not credited, I would get a lower mark for the } \\
\text { whole [subject] as I do not study. }\end{array}$ \\
\hline 12 & One big test at the end of the semester. \\
\hline 13 & Necessary task. \\
\hline 14 & Once in two weeks. \\
\hline 15 & Need more time for me to prepare for the test. \\
\hline 16 & Should be credited. \\
\hline 17 & credited. \\
\hline 18 & I did spend a lot of [time] study[ing] when the tests were \\
\hline 19 & Not weekly test as I forget for the examination. \\
\hline 20 & If they are not credited, I will study for another [subject]. \\
\hline 21 & Small credited tests give a [sense of] comfort that one big \\
& test result does not decide to fail the student. \\
\hline 22 & Credit is not good, as it restricts my own study pace. \\
\hline 23 & Credited tests inspire timely study. \\
\hline
\end{tabular}

As evident in Table IX, both student groups $\mathrm{E}$ and $\mathrm{F}$ had similar perceptions of the vocabulary memorisation task. Students tended to think credited vocabulary tests/checks were a positive motivation booster (Group E Mean 4.26, Group F Mean 4.63) and non-credited tests were less effective as motivation boosters (Group E Mean 2.96, Group F Mean 2.61). This result was also reflected in their final academic results at the end of the semester (for credited tests: Group E Mean 4.26, Group F Mean 4.63, and for non-credited tests: Group E Mean 2.65, Group F Mean 2.95). The subsequent question regarding individual study time for the vocabulary tests showed that if tests were credited the Group E Mean was 4.26 and Group F Mean 4.13 , but if they were non-credited the Group E Mean was 2.83, Group F Mean 2.81, indicating a clear decrease in time spent studying. In summary, students preferred credited vocabulary tests to the non-credited option, based on their belief that credited tests increase motivation, and lead to more study and/or more regular study and a better academic outcome.

For the purposes of this research, students were not only allowed but encouraged to express their opinions without restraint. A total of 23 different comments were collected during the survey, which can be seen in Table X above. The majority of the students' comments regarding the vocabulary tests were positive (Comment No 8). In answering the survey questions, as the student reflected on their experiences of credited and non-credited vocabulary tests over the two semesters in 2015 they were prepared to study more and/or more regularly when the tests were credited. Consequently, when the tests were non-credited, the students said they would not study (Comment No 2 and 3). A number of students saw credited tests as opportunities for them to check their knowledge of vocabulary and as such served as an effective motivation booster (Comment No 4, 7, 16 and 17).

Some students saw a link between regular, credited vocabulary tests and an increase in the likelihood of their attending classes. They suggested that this brings about a positive side effect given that the students' attendance is otherwise non-compulsory. Students are not required to be physically present at all sessions/classes due to the fact that there is a variety of enrolment options and ICT applications in place to enhance the traditional face-to-face teaching/learning style. In other words, students can skip lessons as they wish, without perceiving the risk of an immediate academic disadvantage. Higher education institutions currently avidly encourage independent and autonomous learning. Nevertheless, there are some students who are either not willing or unable to organise/implement their own disciplinary study routines independently, leaving them feeling isolated and unsupported by the structure of a course or learning environment. This research identified vocabulary tests as an indirect impetus to constant class attendance. The student who made Comment No 5 seems aware of the fact that any foreign language course is a skills-based course and as such requires regular reinforcement, revision and study. Skills are built upon progressively, and missing classes at the foundation stage may prevent students from increasing their competence in the language. Hence, students' physical attendance in class is vital, and regular vocabulary tests can provide an incentive to help them keep up a continuous and disciplined study routine (Comment No 9).

Nurturing discipline and commitment to their study prevents students from being apathetic towards class attendance. It can also help them to self-monitor their progress so they can gauge how well they are doing and whether they are likely to complete the course successfully (Comment No 6 and 23). Mastering sufficient vocabulary knowledge is a minimum and crucial requirement for students' successful study and subject completion, and can be achieved through VT and VC. Vocabulary tests and checks automatically create an opportunity for students not only to memorise the target vocabulary but also to discover and correct the orthographical mistakes they make. VT and VC target Japanese lexical items that integrate, in written form, the phonetic characters of Hiragana and Kanji (as Katakana is used for non-Japanese originated words). VT and VC therefore stimulate students' awareness of (in)correct spelling as well as (mis)pronunciation, especially of words that include double vowels, double consonants: $t s u$ and Y-vowel: $y a, y u, y o$, which both stand for a single piece (mora), voiced and semi-voiced consonants, and words with exceptional spelling rules inconsistent with its pronunciation. A learner's misspelling may derive from articulacy phonetic interference because 'Our L1 (mother tongue) interferes with out attempts to function in the L2 (target language)' ([34], p. 9). Although this cannot be explored further in written vocabulary testing targeted for this research, Japanese spelling retains close links to a segment of phonological information, which leads to further investigation to a large extent (e.g., [35], [36]). Misspelling is a signal that students are likely to make phonologically unintelligible mistakes. Thus, significance of vocabulary testing should be taken into consideration in the learning process as it enables students to cultivate a cognitive ability to measure their accuracy in both Japanese orthography and pronunciation.

While the survey results consisted of predominantly positive feedback (especially when the test was organised as a credited task, providing a nonthreatening psychological encouragement towards study), the survey also revealed some drawbacks which highlighted issues related to nonteaching aspects of the course including timetabling during the semester (Comment No 15). The aim of the tests is to assist students to master the list of the target vocabulary and 
expressions on a weekly basis (short-term goal) to be covered eventually by the end of the semester (long-term goal) via an explicit vocabulary teaching approach/instruction. This leads to the cultivation of students' metacognitive activities including a self-regulated semester study plan integrating achievable short- and longterm aims, which is inevitable for second/foreign language education.

Through the identification of their mistakes in the feedback provided by tests, students are able to prepare to avoid the same mistakes which may then result in a better outcome from multiple assessment tasks that account for a considerable portion of their final mark; this advantage does not arise if the final mark is determined by a single end-ofsemester examination. Regular smaller tests may lead students to succeed in the subject and avoid failing. This was confirmed by one student's comment (Comment No 21) that 'small credited tests give a [sense of] comfort that one big test result does not decide to fail the student'. In other words, the students are provided with more chances to gain credit, and it is not only one examination that decides success or non-success in the subject. Another student seems to be fully aware of his/her own ineptitude in study and consequently saw the vocabulary tests as an opportunity to increase the marks and pass the subject. The student specifically commented that 'If they are not credited, I would get a lower mark of the whole [subject] as I do not study' (Comment No 11).

There are other unique student insights uncovered in this survey of their perceptions of credited and non-credited vocabulary tests. One student explained that 'I did spend a lot of (time) studying when the tests were credited' (Comment No 18). Due to the fact that the vocabulary tests taken in Semester 1 were non-credited, this student confessed to not giving enough effort to those held in Semester 2, 2015. This suggests an assumption among students that non-credited assignments are viewed negatively as unimportant. Thus positive pressure on students is required when it comes to assignments.

Similar to the above-noted student, another one also admitted a change in attitude after the test condition was altered from non-credit to credit bearing. 'If they were not credited, I would study another [subject]' (Comment No 20). This can be interpreted to mean that students studied for the vocabulary tests because they were credited assignments in Semester 1, unlike the non-credited assignments in Semester 2,2015 . However, the time freed up by the choice not to study for the vocabulary test may not have been spent studying for another subject. This is also relevant in other situations, such as towards the end of the semester when the due date for multiple assignments is approaching. Support for this interpretation of this student's comment is the fact that this student did the survey in the last teaching week of Semester 2, 2015.

One student expressed the view that 'a credited test is not good as it restricts my own study pace' (Comment No 22). However, this particular student was taking the $2^{\text {nd }}$ year Japanese subject as an elective despite possessing higher level Japanese language skills. This student's major aim was not, therefore, to obtain the highest possible mark for the subject but to obtain a pass with the least amount of effort.
Due to the fact that this student had already mastered most of the target vocabulary, they were confident with catching up easily towards the end of the subject and pass the end-ofsemester examination. As for the isolated comment, 'The credited test is worth too much value' (Comment No 10), the subject coordinator was originally concerned with this student's perspective $(30 \%$ of the whole subject mark in Semester 2, 2014). The unexpected time-consuming official protocol for him to change this assignment weightage was the cause; the problem was solved in Semester 1, 2015.

Although, the majority of the students found the weekly vocabulary tests a beneficial and necessary component of the course (Comment No 13), irrespective of whether or not they were credited or non-credited (Comment No 1), preferences for test frequency varied, such as 'Once in two weeks' (Comment No 14). However, less frequent vocabulary tests held during the semester may lead to a broader target vocabulary area for students to memorise. Some students explicitly indicated that they preferred to take less frequent vocabulary tests such as 'One big test at the end of the semester' (Comment No 12) or 'Not weekly test as I forget for the exam' (Comment No 19). However, it is not practical to lower test frequency drastically unless the target vocabulary area is reduced, considering the fact that most students attempt to memorise the vocabulary on the day before the vocabulary test.

\section{CONCLUSION}

The research results indicate that the format of the vocabulary tests (credited or non-credited towards their result) did not affect the 1st year students' approaches to their study of vocabulary, although it did have an effect on the 2nd year students'. As for the frequency of the tests, once a week was preferred by many in both 1st year and 2nd year student groups. In other words, in the case of 2 nd year student vocabulary learning, weekly credited vocabulary tests resulted in positive learning outcomes and met students' expectations of the course. These results mean that adhering to the university's conditions for assignment tasks had a negative impact on the students' behaviour and attitudes in terms of motivation for learning, academic outcomes and study time, depending on their levels. Thus, the vocabulary tests which form part of the Japanese course should be returned to their former credited-bearing status, as such a shift would promote learning and the best academic outcomes for the students.

It is common in most universities in Australia for the central management to be led by the school's or faculty's senior executive management teams. This system does not apply only to the administration of higher educational institutions but also to the teaching practices in the classrooms. It is common to overlook the validity and appropriateness of assignment tasks designed by teaching staff with expert subject knowledge, reinforced by theoretically established teaching and learning methodology, as if one rule fits all subjects. The researcher is primarily concerned about this tendency with its associated insufficient scrutiny of a particular subject's content, the level of study and the academic discipline, and current students' learning patterns. In the case of Japanese as a 
second/foreign language, this research has shown that students at a certain stage of learning favour creditedbearing tests over non-credit earning ones, and consider the former to be more affective for improving their academic performance.

The centrally organised system may function effectively in terms of student learning outcomes and achievements, with student progress in academic disciplines measured by common assessment tasks. It is, however, still doubtful whether the university's organisational practice based on this theory can be implemented fully and successfully, as university academic disciplines involve not only the transdisciplinary and cross-disciplinary but also the multidisciplinary and interdisciplinary fields. The results from this research also suggest a need to carefully reconsider the management theory applied currently to assessment procedures in all subjects and levels within each of the subjects.

\section{REFERENCES}

[1] M. Cudmore. (2005). A model for setting student to teaching staff ratio targets. [Online]. Available: http://www.aair.org.au/app/webroot/media/pdf/AAIR\%20Fora/Forum 2005/Others/Cudmore.pdf

[2] J. Rowbotham. (November 2, 2011). Student-staff ratios ballooning. The Australian Higher Education. [Online]. Available: http://www.theaustralian.com.au/higher-education/student-staffratios-ballooning/story-e6frgcjx-1226182968247

[3] P. Nation, Teaching and Learning Vocabulary, Boston, MA: Heinle and Heinle Publishers, 1990.

[4] H. D. Brown and H. Lee, Teaching in Principles: An Interactive Approach to Language Pedagogy, $4^{\text {th }}$ ed. New York, NY: Pearson Education, 2015

[5] K. Folse, (2004). "Myth about teaching and learning second language vocabulary: What recent research says: Applying second language research to classroom teaching," TESL Reporter, vol. 37, no. 2, pp. 113 .

[6] K. Folse. (2004). "The underestimated importance of vocabulary in the foreign language classroom," CLEAR News. [Online]. 8(2). p. 1, 3 , 6. Available: http://www.seasite.niu.edu/trans/articles/Underestimated\%20Importa nce $\% 20$ of $\% 20$ Vocab.htm

[7] K. Folse, Vocabulary Myths: Applying Second Language Research to Classroom Teaching, Ann Arbor, MI: The University of Michigan Press, 2004.

[8] J. Hulstijn, "Retention of inferred and given word meanings: Experiments in incidental vocabulary learning," in Vocabulary and Applied Linguistics, P. Arnaud, and H. Bejoint, Eds. London, UK: Macmillan Academic and Professional Limited, 1992, pp. 113-125.

[9] B. Harris, (2014). Corporatisation, managerialism and the death of the university ideal in Australia. Journal of Politics and Law. [Online]. 7(2). $\quad$ pp. 63-80. Available: http://www.ccsenet.org/journal/index.php/jpl/article/view/37462/2100 1

[10] L. Morris. (2005). Performance appraisals in Australian universitiesimposing a managerialistic framework into a collegial culture. AIRAANZ 2005. [Online]. pp. 387-393. Available: http://airaanz.econ.usyd.edu.au/papers/Morris.pdf

[11] P. Nation, Learning Vocabulary in another Language, Cambridge, UK: Cambridge University Press, 2001.

[12] V. P. Takac, Vocabulary Learning Strategies and Foreign Language Acquisition, Cleveton, UK: Multilingual Matters, 2008.

[13] T. Lamb, "Learner Autonomy and Teacher Autonomy: Synthesising an Agenda," in Learner and Teacher Autonomy, T. Lamb, and $\mathrm{H}$ Reinders, Eds. Amsterdam, Netherlands: John Benjamins Publishing Company, 2008, pp. 269-284.

[14] H. Reinders and C. White, "20 years of autonomy and technology: How far have we come and where to next?" Language Learning and Technology, vol. 20, no. 2, pp. 143-154, 2016.

[15] Independent Learning. (2014). [Online]. Available: https://www.heacademy.ac.uk/system/files/resources/independent_lea rning.pdf
[16] P. Blumberg and J. Everett, "Achieving a campus consensus on learning-centered teaching: Process and outcomes," To Improve the Academy, vol. 23, pp. 191-210. 2005.

[17] P. Blumberg. Implementing learning centered approaches in your $\begin{array}{lll}\text { teaching. } & \text { [Online]. }\end{array}$ https://www.usciences.edu/teaching/LearnerCentered/implementing\%20lct.pdf

[18] K. Sinhaneti and E. K. Kyaw. (2012). A study of the role of rote learning in vocabulary learning strategies of Burmese students. USChina Education, Review A 12. [Online]. pp. 987-1005. Available: http://files.eric.ed.gov/fulltext/ED539350.pdf

[19] M. J. McCarthy, A. O'Keeffe, and S. Walsh, The Vocabulary Matrix: Understanding, Learning, Teaching, Hampshire, UK: Heinle Cengage Learning, 2008.

[20] A. O'Keeffe, "Vocabulary instruction," in The Cambridge Guide to Pedagogy and Practice in Second Language Teaching, A. Burns, and J. C. Richards, Eds. New York, NY: Cambridge University Press, 2012, pp. 236-245

[21] R. Waring. (2002). "Scales of vocabulary knowledge in second language vocabulary assessment," Kiyo, The Occasional Papers of Notre Dame Seishin University. [Online]. Available: http://www.robwaring.org/papers/various/scales.htm

[22] T. Paribakht and M. Wesche, "Reading comprehension and second language development in a comprehension-based ESL program," TESL Canada Journal, vol. 11, no. 1, pp. 9-29, 1993.

[23] M. Wesche and T. S. Paribakht, "Assessing second language vocabulary knowledge: Depth versus breadth," Canadian Modern Language Review, vol. 53, no. 1, pp. 13-40, 1996.

[24] E. Dale, "Vocabulary measurement: Techniques and major findings," Elementary English, vol. 42, no. 8, pp. 895-901, 1965.

[25] K. A. Dougherty Stahl and M. A. Bravo, "Contemporary classroom vocabulary assessment for content areas," The Reading Teacher, vol. 63 , no. 7 , pp. $566-578,2010$.

[26] K. Koda, "Orthographic knowledge in L2 lexical processing," in Vocabulary Acquisition, J. Coady, and T. Huckin, Eds. Cambridge, UK: Cambridge University Press, 1997, pp. 35-52.

[27] P. Nation and J. Newton, "Teaching vocabulary in second language," in Vocabulary Acquisition, J. Coady, and T. Huckin, Eds. Cambridge, UK: Cambridge University Press, 1997. pp. 238-254.

[28] S. Webb, "Receptive and productive vocabulary learning: The effects of reading and writing on word knowledge," Studies in Second Language Acquisition, vol. 27, no. 1, pp. 33-52. 2005.

[29] S. Webb, "The effects of receptive and productive learning of word pairs on vocabulary knowledge," RELC Journal, vol. 40, no. 3, pp. 360-376. 2009.

[30] P. Nation, New Ways in Teaching Vocabulary, Alexandria, VA Teachers of English to Speakers of Other Languages, Inc. (TESOL) 1994.

[31] S. J. Ehsanzadeh, "Depth versus breadth of lexical repertoire: Assessing their roles in EFL students' incidental vocabulary acquisition," TESL Canada Journal, vol. 29, no. 2, pp. 24-41, 2012.

[32] S. Hatami and M. Tavakoli, "The role of depth versus breadth of vocabulary knowledge in success and ease in L2 lexical inferencing," TESL Canada Journal, vol. 30, no. 1, pp. 1-21, 2012.

[33] R. DeKeyser and R. Criado, "Automatization, skill acquisition, and practice in second language acquisition," in The Encyclopedia of Applied Linguistics, C. Chapelle, Ed. London, UK: Blackwell Publishing Ltd, 2013, pp. 323-331.

[34] J. C. Wells, "Overcoming phonetic interference," English Journal of the English Phonetic Society of Japan, vol. 3, pp. 9-21, 2000.

[35] R. Hayes-Harb and K. Masuda. "Development of the ability to lexically encode novel second language phonemic contrasts," Second Language Research, vol. 24, no. 1, pp. 5-33, 2008.

[36] K. Ishikawa, "Syllabification of intervocalic consonants by English and Japanese speakers," Language and Speech, vol. 45, no. 4, pp. $355-385,2002$.

Hiroshi Hasegawa has a Graduate Diploma in Education (Language Teaching) completed in 1996 (University of Technology, Sydney), Master of Education Studies (LOTE) in 1997 (University of Tasmania), Master of Education (TESOL) in 1998 (University of Tasmania) and a $\mathrm{PhD}$ in Education in 2005 (University of Tasmania).

Dr. Hasegawa is currently a senior lecturer in the School of Education at Curtin University in Western Australia. He coordinates and teaches undergraduate units pertaining to Japanese (as a second language) and culture, and supervises postgraduate students and students completing their teaching practicum. His research interest includes second/foreign language education, ethics and education, enhancement of education through ICT-led educational reform. 